\title{
Coal and Gas Outburst Accident Virtual Escape System for Miners Based on Virtools
}

\author{
Bo Tan ${ }^{1,2,}{ }^{*}$, Zhen Zhang ${ }^{2}$ and Xiaofeng Qin ${ }^{2}$

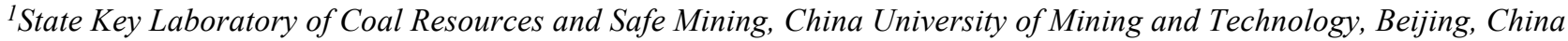 \\ ${ }^{2}$ Faculty of Resource and Safety Engineering, China University of Mining and Technology (Beijing), Beijing, China
}

\begin{abstract}
In order to improve the survival skills of miners faced with coal and gas outburst accident, and enhance the systemic security of mining personnel's safety training, a virtual survival training system has been designed and developed, which applies the technology of Virtual Reality on the basis of Virtools. This paper introduces the virtual reality system design and implementation process, the main developmental tools and the solution of key technology, implements the three-dimensional visualization of the process of coal and gas outburst and underground escape. Practice shows that the system can create immersive sense of reality in the users, make the escape routes more impressive, grasp the method of self-help, make miners in-depth understanding of the various forms of coal and gas outburst accident, understand the accident process, thereby reducing the serious consequences of the accident. The development and application of the virtual survival training system provide a brand-new thought for coal mine safety training enhancement by making the training process interesting and interactive, hence making up for the deficiency of the conventional safety training.
\end{abstract}

Keywords: Index Terms — coal and gas outburst, Virtools, Safety training, Virtual survival training system, Three-dimensional visualization.

\section{INTRODUCTION}

Coal and gas outburst will spew out huge quantities of coal and gas within a very short period of time in the roadway, beside its being also destructive and unpredictable, threatening the life safety of the miners seriously. In order to ensure that the underground staff can evacuate safely after the accident, in advance they must be familiar with the escape route and methods to protect themselves. But in the traditional escape training, underground staff was often required to remember the two-dimensional escape route mechanically in a boring and abstract form. Thus the training effect was often unsatisfactory. Miners are often at a loss without any self-help reaction in the case of extreme panic, when the accident happened. The virtual reality technology can create a realistic underground environment and simulate the coal and gas outburst accident to make a visual disaster scene in which the miner can feel the risk and danger [1,2].

At present, virtual reality technology in the field of mine safety is mainly focused on production training, mine roaming and accident simulation, etc. In regard to the problem of miner escape after destructive accident in the coal mine, many scholars have conducted in-depth researches on the issues of mathematical model of miner escape and escape route algorithm. But most of these studies are limited to cal-

*Address correspondence to this author at the State Key Laboratory of Coal Resources and Safe Mining of China University of Mining and Technology, Beijing, 100083 China; E-mail: tanbo709@126.com culating and designing the two-dimensional escape routes, focused on providing the basis for mine managers to draw up escape plan and post-disaster emergency treatment. The research of virtual evacuation training of miner is relatively rare [3]. This paper mainly studies how to apply virtual reality technology to the safety training of coal and gas outburst and introduces the process of design and development of the virtual training system based on the Virtools platform.

\section{SYSTEM DEVELOPMENT PROCESS}

Firstly, to organize and design the technical information of escape scene through the relevant literature and cases of coal and gas outburst accidents, which include development process of coal and gas outburst accident, phenomenons and characteristics of the outburst accident, the damage degree of the roadway and personnel, the best method and route to escape. Then the established methods of 3D models including mine roadways, miners, electromechanical equipments and refuge chamber, are studied. Finally, coal and gas outburst accident simulation and virtual survival training system can be realized through importing models to Virtools. Fig. (1) shows the system development process.

\section{DIVISION OF SYSTEM FUNCTION MODULE}

According to the development requirements, the virtual system adopts structured method and prototyping method of software engineering development to divide the system function module top-down. The sub module of the bottom is set 


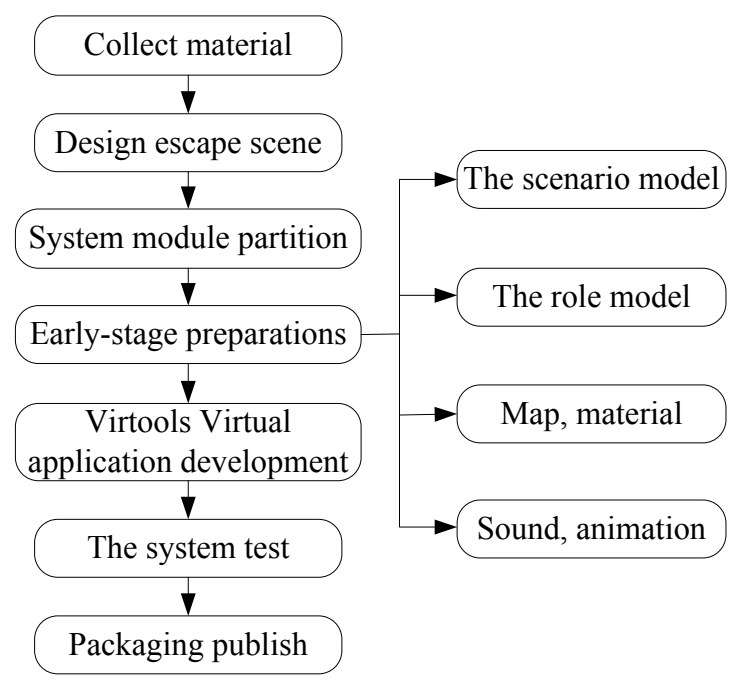

Fig. (1). System flowchart.

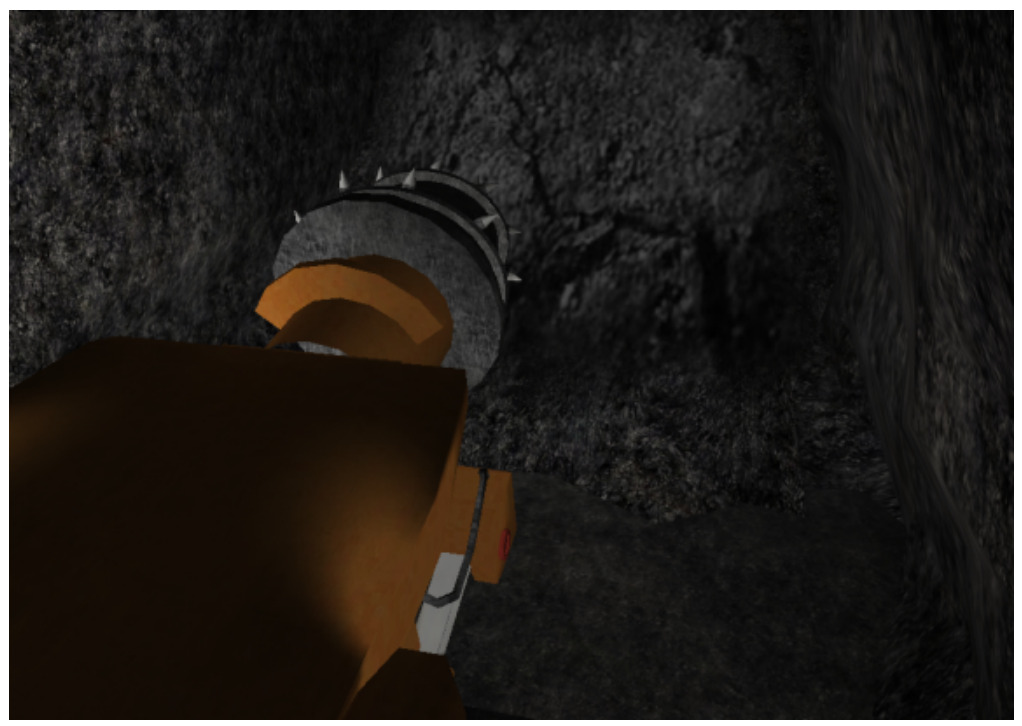

Fig. (2a). Working surface cracks omen.

up firstly, then the application oriented upper modules are formed by connecting the sub modules. The virtual system includes the sub system of virtual escape training and the sub system of evacuation assessment. According to coal and gas outburst accident and the general characteristics of escape, the sub system of virtual escape training includes the module of accident simulation and the module of evacuation training. The sub system of evacuation assessment includes three modules to simulate and train the process of escape after the coal and gas outburst accident $[4,5]$.

\subsection{Accident Simulation Module}

The module of accident simulation mainly simulates the process of coal and gas outburst. The three-dimensional modeling and animation of this module is made by 3D Max and Virtools. It can perform the occurrence, development process and consequence of the accident. For example, Tunneling working surface cracks that occur before the accident of outburst, are shown in the Fig. (2a). The scene of outburst is shown in the Fig. (2b). With this module, people can get intuitive understanding of the process of coal and gas outburst accident and the huge destructive power.

\subsection{Evacuation Training Module}

This module of evacuation training is mainly used to make the user familiar with the underground roadway and the process of escape. In this module, the vision of roadway in the escape scene is relatively clear. At the same time, there are indicating arrows of the escape route and large map of underground roadway for navigation. Prompt windows will automatically appear when needing the user to make decisions or operate equipment. According to the prompt, the user can complete the escape task relatively easily and be familiar with the system. Parts of the evacuation training scene are shown in the Fig. (3a) and Fig. (3b). 


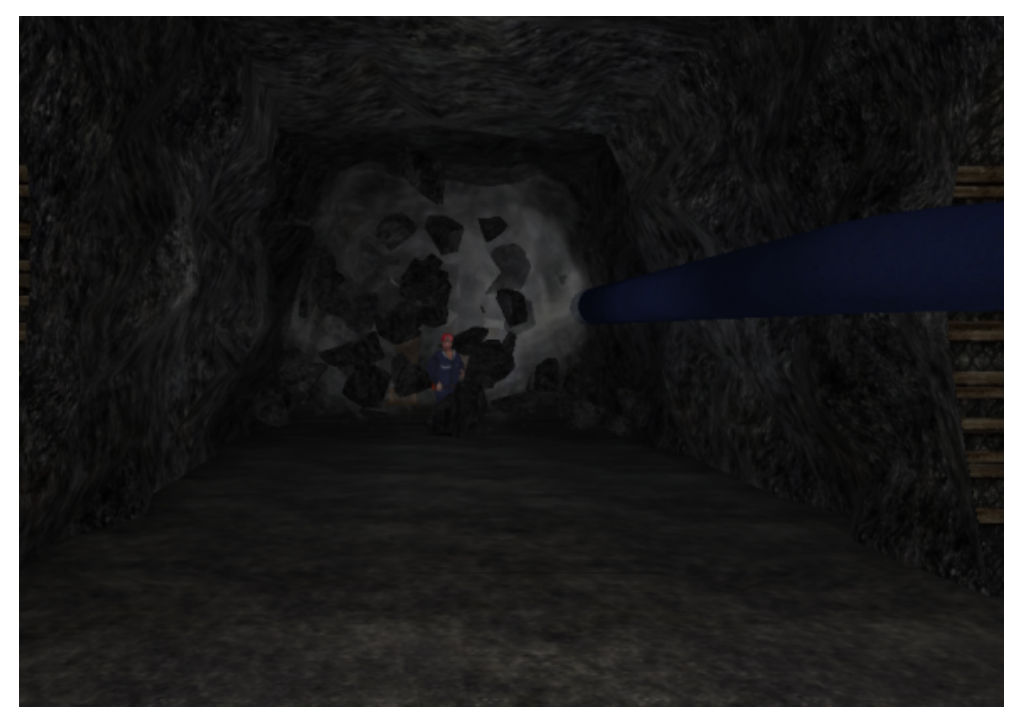

Fig. (2b). Scene of outburst.

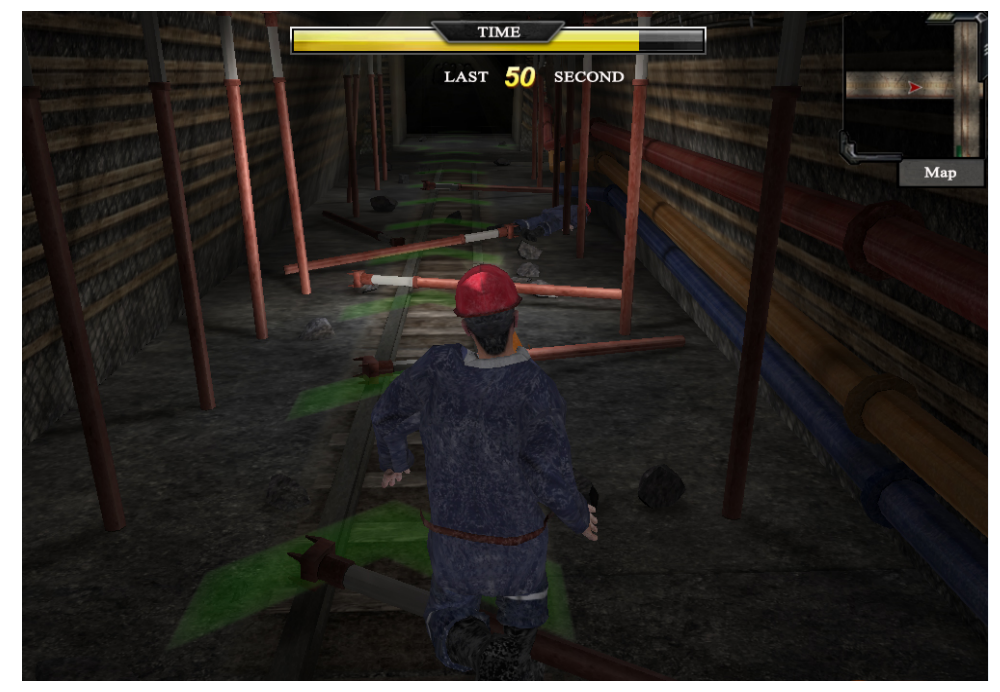

Fig. (3a). Escape route navigation.

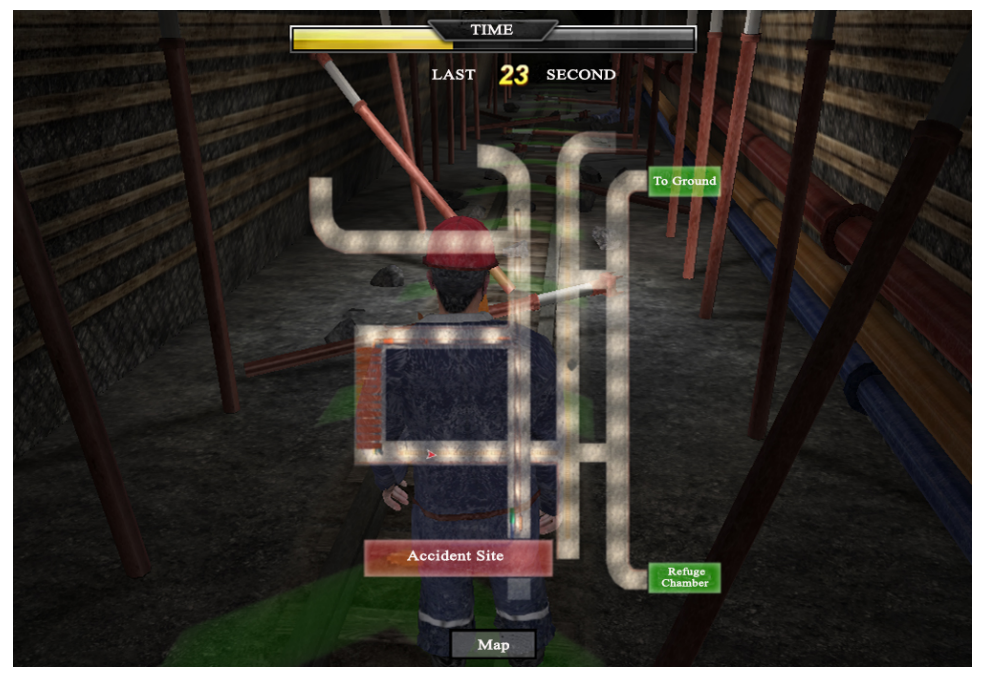

Fig. (3b). Underground map. 


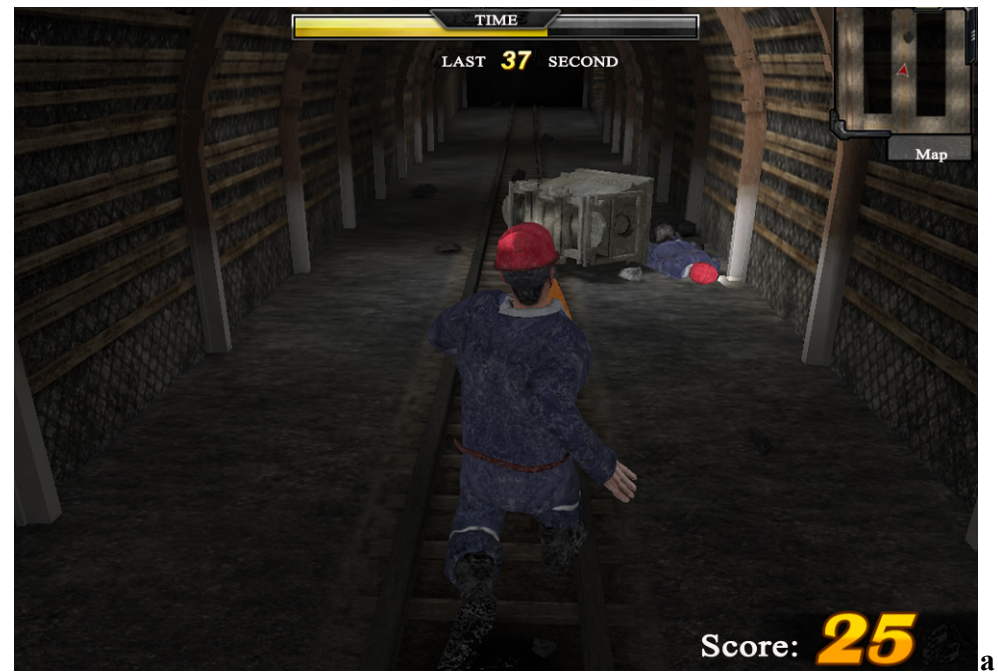

Fig. (4a). Escape from the accident.

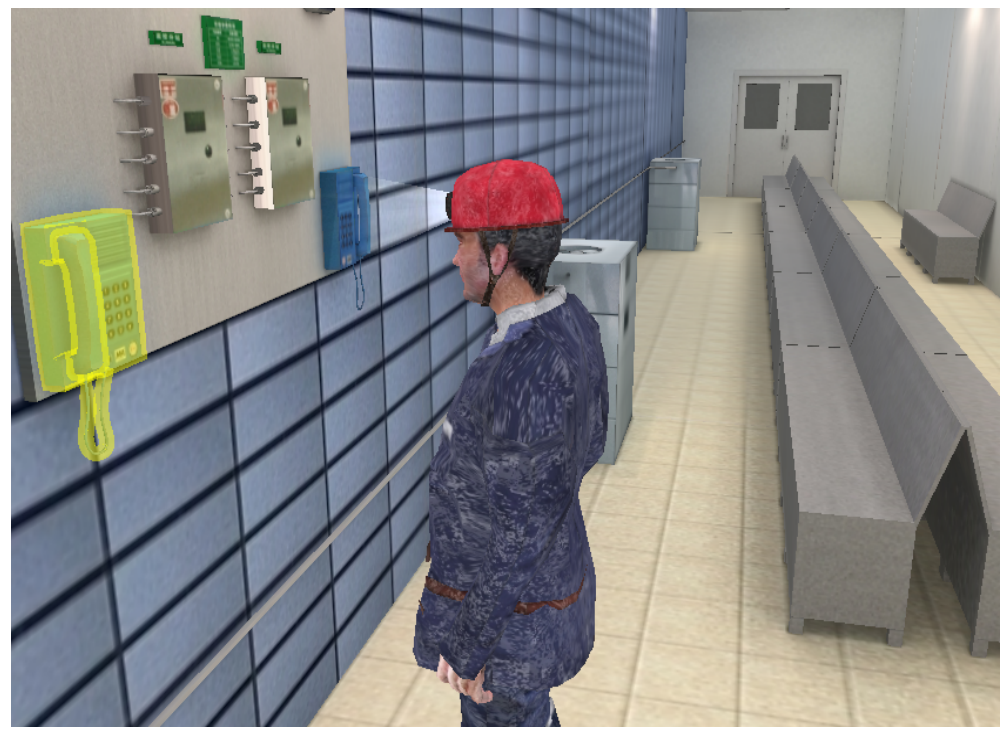

Fig. (4b). Scene of refuge chamber.

\subsection{The Sub System of Evacuation Assessment}

The sub system of Evacuation Assessment is mainly used for the quantitative assessment of the escape ability of miner in the form of score in a virtual coal and gas outburst accident. In this module, the vision in the escape scene is relatively obscure and there is no navigation or prompt to help the user. In order to complete the escape task and get a high score, the user must chose the rational escape route in time and operate equipment correctly. The emphasis of the assessment is on the use of the self-rescuer, the selection of escape route, the use of refuge chamber and self-rescue behavior, etc. Parts of the assessment module scene are shown in the Fig. (4a) and Fig. (4b).

\section{SYSTEM DEVELOPMENT TOOL}

Virtools is a highly interactive 3D visual simulation platform, which is developed by Dassault Company in France. A 3D scene with abundant contents and strong interactivity can be created quickly and easily by using Virtools through integrating various kinds of files such as sounds, text, video, animation, model, etc. Various kinds of reusable behavior have been integrated extensively through this platform. Users, who have no programming experience, can easily create various types of interactive systems with a simple and clear interface diagram editor. For advanced users, a new Virtools Scripting Languages (VSL) module can be created through Virtools Software Development Kit (SDK), the module can be used by adding to the interface diagram editor $[6,7]$.

\section{REALIZATION OF SYSTEM FUNCTION}

\subsection{Constructs of Escape Scene}

To achieve a good effect of virtual training, firstly, the models such as roadway, hydraulic support, coal cutter and belt conveyor should be created by 3D Max modeling software, and the animation of outburst in the heading face 


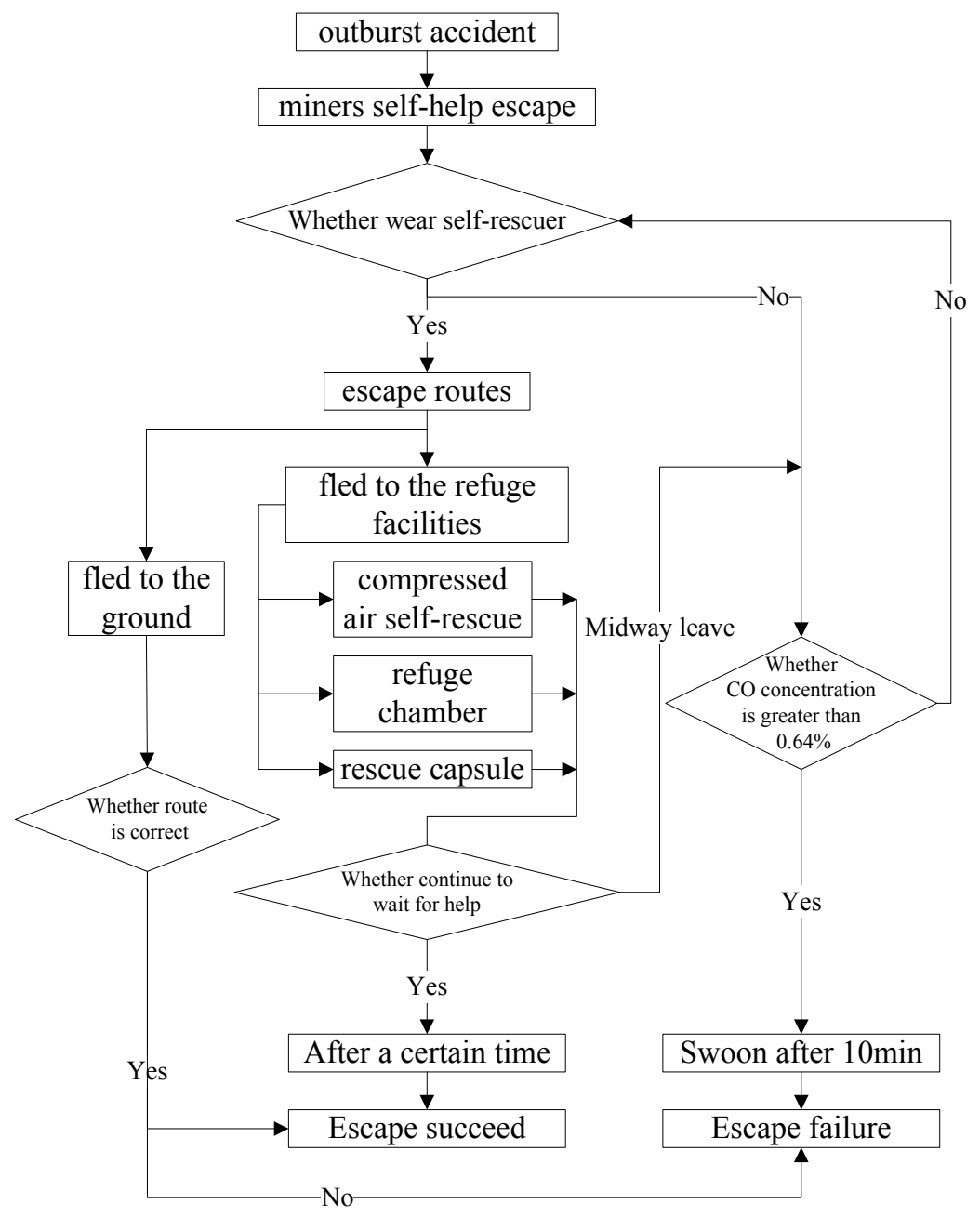

Fig. (5). Escape process flowchart.

should be designed. Then, relevant miners character models are established, to use skin technology to make bones synchronize with characters, to design working, walking, running and other actions by using key frames, and through the Virtools own plug-in export to the material library [8]. Finally the established models, materials and actions are integrated into Virtools scene, and so a complete system of miners escape scene in coal and gas outburst accident can be made up.

In order to enhance the effects of realistic escape, the following aspects should be especially considered:

\subsubsection{The Sensory Effects of Visual and Auditory}

After coal and gas outburst accidents, the power supply equipments are vulnerably destroyed by outburst coal or blast wave in disaster area. At this time, since it is pitch-dark in roadway, so when the escape is performed, diffuse reflection and self-illumination of roadway and main equipment materials should be dimmed as much as possible in this scene (Reference value R: $50 \mathrm{G}$ : 50B: 50). At the same time, a variety of sound effects are added to enhance sensory dimensions and escape tension, such as the background sound of escape, wheeze and footsteps in running time, the time countdown tick, etc.

\subsubsection{The Effects of Collision Detection}

The collision detection is an extremely important factor for eventual authenticity and operability of virtual reality system. Excellent collision detection response setting can enhance the sense of reality and immersion in virtual worlds. For example, persons cannot escape through the roadway, electrical and mechanical equipments and other obstacles; when at the foot of coal or rock, the action of roles being tripping is activated by the collision detection.

\subsubsection{The Rationality of Escape Process}

The escape scene should present the correct steps of escape and self-rescue and possess complete self-rescue equipment in order to increase the significance of virtual training. On the one hand, after the accident, the miners only timely and correctly wear self-rescuer before they can start looking for escape routes, otherwise they would be suffocated because of excessive gas content. On the other hand, in terms of routes selection, miners can choose to escape from the mine to the ground or choose the refuge facilities to escape from disaster areas according to their own decisions. The Fig. (5) shows flowchart of miners self-rescue escape process. 


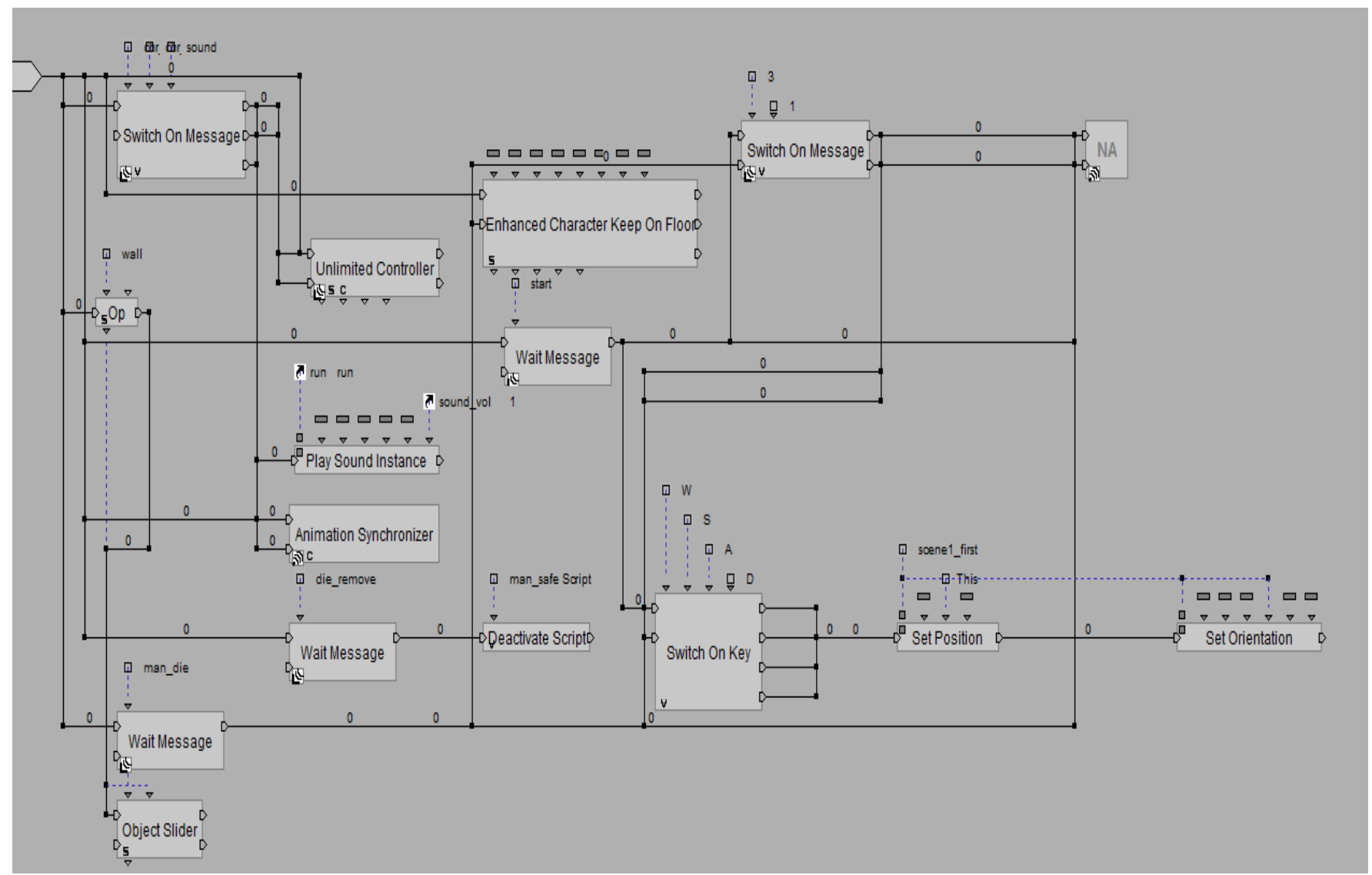

Fig. (6). Role control script.

\subsection{Evacuation Training Function Implementation}

To control miners to realize the virtual escape in Virtools, the following camera, mouse response, keyboard response, collision detection and the other factors should be set, in which the changing of the direction of the camera view is controlled by the mouse, the location movement of the angle position of the camera is controlled by the keyboard, the collision detection keeps the camera in the roadway, and the small arrow in the small map synchronously displays controller position in the roadway.

In the script of keyboard control, the corresponding keys are set by the module of BB (Building Block) in the Switch On Key. In the export of the corresponding keys, the behavior module of translate is connected to control the displacement and set the corresponding displacement vector. In the script of mouse response, the mouse trigger messages are activated by the module of BB of Switch On Key, the X and $\mathrm{Y}$ axial displacement of the mouse on the screen can be get by Get Mouse Displacement, the rotation (Rotate) angle of the camera can be transformed through multiplication into the rotation of the camera Angle (Rotate) perspective and the $\mathrm{Y}$ constraint is set through the combination of Get Component Threshold and Set Orientation, which can prevent the angle of rotation from becoming large. In the collision detection, first, the object will be collided into groups, and then the collision detection will be implemented by the Object Slide. In this module the first parameter is set to the collision radius, in which the greater the value set, the more the safety distant of collision between the role and the wall will be . The second parameter is set to the collision of group. Fig. (6) shows the script of the role control [9].

\section{CONCLUSION}

The design and implementation method of personnel virtual accident escape system in mine coal and gas outburst are studied, and 3D visualization of the process of coal and gas outburst , and underground personal escape are realized. The following conclusions are drawn:

1. Through immersion experience of coal and gas outburst accident in virtual coal mine, the operator can truly feel the danger level of accident scene and enhance their knowledge and understanding of coal and gas outburst to help them overcome their fears.

2. It has good effects on improving the underground workers' abilities of escape and self-rescue disaster treatment operated by virtual people wearing self-rescuer, choosing escape routes and showing a series of escape behaviors.

The outburst accident scene that is created by coal and gas outburst accident personnel virtual system of escape training, has strong sense of reality and shock power. And escape after disaster training system has a good sense of interactivity and immersion. It greatly enriches the content and form of mine safety training, improves the effectiveness of training and is worth further promoting and using in the actual production. 


\section{CONFLICT OF INTEREST}

The authors confirm that this article content has no conflict of interest.

\section{ACKNOWLEDGEMENTS}

This work is supported by National Natural Science Foundation of P. R. China (U1261214).

\section{REFERENCES}

[1]

D. Wang, Z. Wu, and W. Du, "Application of virtual reality technology in mine production simulation system," Coal Mine Machinery, vol. 27, pp. 172-173, Oct. 2006.

[2] Y. Yu, J. Zhang, and B. Zheng, "Simulation system based on VR for training technicians and workers in surface mining," Express Information of Mining Industry, vol. 442, pp. 31-33, April 2006.
[3] Y. Ling, X. Cheng, "Three-dimensional geological visualized model and its applications," Energy Technology and Management, no. 6, pp. 50-52, 2007.

[4] L. Wang, "The distributed VR technology based on VIRTOOLS," Journal of Hubei University of Technology, vol. 20, no. 3, pp. 2224, 2005.

[5] W. Zeng, and B. Jiang, "Mine personnel training system based on virtual reality technology," In: Collected Paper of the 2008 Coal Mine Safety Annual Meeting in China, Xuzhou, China University of Mining Press, October, pp. 268-271, 2008.

[6] D. Weidlich, L. Cser, T. Polzin, D. Cristiano, and H. Zickner, "Virtual reality approaches for immersive design," CIRP Annuals Manufacturing Technology, vol. 56, pp. 139-142, 2007.

[7] Z. Hua, H. Fan, "Research on mining airiness system visual based on virtual reality," Metal Ming, vol. 7, no. 1, pp. 53-56, 2003.

[8] G. Si, "Research on VR Mining Working Training System," Master's degree thesis, Haerbin University of Technology, 2003.

[9] M. Liu, Design of 3D Games, ChongQing: Sichuan publication Group- Publication Center of Sichuan Electron Audio and Video, 2005 .

Received: September 16, 2014

Revised: December 23, 2014

Accepted: December 31, 2014

(C) Tan et al.; Licensee Bentham Open.

This is an open access article licensed under the terms of the Creative Commons Attribution Non-Commercial License (http://creativecommons.org/licenses/bync/4.0/) which permits unrestricted, non-commercial use, distribution and reproduction in any medium, provided the work is properly cited. 